\title{
Non-linear elastic model for MSW considering dilatancy effect
}

Han Ke

Professor, Institute of Geotechnical Engineering, Zhejiang University, Hangzhou, China

\section{Yun-Min Chen}

Professor, Ministry of Education Key Laboratory of Soft Soils and Geoenvironmental Engineering, Institute of Geotechnical Engineering, Zhejiang University, Hangzhou, China (corresponding author: chenyunmin@zju.edu.cn)

\author{
Ding Dong \\ Institute of Geotechnical Engineering, Zhejiang University, Hangzhou, China \\ Cheng Guo \\ Guizhou Transportation Planning Survey \& Design Academe Co. Ltd, \\ Guiyang, China \\ Shi-Jin Feng \\ Professor, Department of Geotechnical Engineering, Tongji University, \\ Shanghai, China
}

Study of the stress-strain behaviour of municipal solid waste (MSW) is important in landfill design and management. Non-linear elastic constitutive models are usually in a simple form and convenient in engineering applications; however, most existing non-linear elastic models do not adequately consider the dilatancy behaviour, which has a significant influence on the strength and deformation behaviours of MSW. In this paper, a non-linear elastic model for the prediction of stress-strain behaviour of MSW is proposed based on the results of consolidated drained triaxial compression tests. The influence of dilatancy behaviour is identified and highlighted. The generalised shear stress can be normalised well by dividing the shear stress by the power function of the mean normal stress. Total expressions of normalised volumetric strain and generalised shear strain were established, and the dilatancy modulus and hardening modulus of the proposed model were obtained. The proposed model was used to simulate test results obtained from both published studies and the authors' laboratory testing. The simulation results were in good agreement with the experimental values in general, although deviations were observed in the simulations of volumetric strain or shear stress for the high-dispersion characteristics of MSW.

\author{
Notation \\ $A_{\mathrm{f}}$ \\ values of pore-pressure coefficient $A$ when the \\ specimens are sheared to different levels of \\ axial strain \\ G shear modulus $(\mathrm{kPa})$ \\ $G_{\mathrm{p}} \quad$ hardening modulus $(\mathrm{kPa})$ \\ $H \quad$ dilatancy modulus $(\mathrm{kPa})$ \\ $K \quad$ bulk modulus (kPa) \\ $p \quad$ mean normal stress $(\mathrm{kPa})$ \\ $p_{1} \quad$ specified isotropic confining pressure $(\mathrm{kPa})$ \\ $q \quad$ deviatoric stress or shear stress $(\mathrm{kPa})$ \\ $V_{0} \quad$ initial volume of the specimen $\left(\mathrm{mm}^{3}\right)$ \\ $V_{1}, V_{2} \quad$ volume of consolidated state under isotropic \\ confining pressures of $p_{1}$ and $p_{1}+\Delta p$, \\ respectively $\left(\mathrm{mm}^{3}\right)$ \\ $\gamma \quad$ generalised shear strain \\ $\varepsilon_{\mathrm{V}} \quad$ volumetric strain \\ $\varepsilon_{\mathrm{V}}^{\prime} \quad$ volumetric strain based on the consolidated state \\ under specified confining pressures \\ $\varepsilon_{\mathrm{Vo}}, \lambda_{1}, a, c, m$ simulating parameters \\ $\varepsilon_{\mathrm{Vp}}, \varepsilon_{\mathrm{Vq}} \quad$ volumetric strain generated by mean normal stress \\ and shear stress, respectively \\ $\varepsilon_{\mathrm{V} 1}, \varepsilon_{\mathrm{V} 2} \quad$ volumetric strain under isotropic confining \\ pressures of $p_{1}$ and $p_{1}+\Delta p$ based on the \\ unstressed state, respectively
}

\section{Introduction}

The stress-strain behaviour of municipal solid waste (MSW) affects many aspects of landfill design and operation, including deformation analysis of landfills, the integrity of the cover and appurtenant systems, stability analysis of landfills, the generation and dissipation of pore-water pressure in MSW and so forth (Babu et al., 2010; Lopes, 2014; Machado et al., 2002; Rowe, 2014). Unlike general soils, MSW exhibits many specific properties, such as the following.

- Non-linear shear strength. MSW exhibits obvious non-linear shear strength properties with an increase in shear strain.

Strain-hardening behaviour can also be observed in the curve of shear stress against shear strain (Singh and Fleming, 2011; Zhang et al., 2014).

- High failure strain. Failure will be absent even when the strain level is over $30 \%$, and shear strength envelopes should be derived on the basis of the strain (Bray et al., 2012; Machado et al., 2002).

- Dilatancy. The volume of MSW specimens will be notably reduced when subjected to a deviatoric stress system namely, dilatancy. The dilatancy behaviour of MSW is identified and highlighted in this paper.

- Biodegradability. The biodegradation of MSW will lead to the loss of solids and will have an influence on the deformation behaviour of MSW, particularly during the secondary compression of landfill settlement (Chen et al., 2009; Wall and Zeiss, 1995). The time-dependent behaviour of MSW is not covered in this paper.

- High dispersion. The strength and deformation behaviours of MSW can be affected by many factors, such as composition, moisture, void ratio, confining pressure, stress history and 
drainage condition. Different stress-strain responses in consolidated drained (CD) triaxial compression tests made by various researchers are presented in Figure 1(a). Remarkable differences can be seen between different MSW samples or under different experimental conditions, indicating the high dispersion of MSW. The stress-strain responses normalised by dividing the shear stress by the confining pressure of the samples are presented in Figure 1(b). It can be seen that the dispersion becomes lower, particularly under a lower strain level, indicating that the confining pressure has a significant influence on the stress-strain behaviour of MSW. Under a higher strain level, great differences can still be seen.

Therefore, it is almost impossible to use a unified constitutive model to fit the stress-strain behaviour of all MSWs.

Furthermore, it is difficult to avoid technical difficulties in sampling high-quality undisturbed MSW specimens for laboratory testing. All the characteristics mentioned earlier lead to difficulties in characterising the deformation properties of MSW (Lopes and Gomes, 2013).
Some traditional soil mechanics constitutive models have been modified and applied in simulations of the deformation properties of MSW or numerical analyses of landfills. Currently, most MSW constitutive models are established using one of the following two methods. The first adopts the theory of non-linear elasticity and has been used in the elastic-hyperbolic model (Filz et al., 2001; Reddy et al., 1996; Singh and Fleming, 2011; Singh et al., 2009), the composite exponential model (Chen et al., 2009) and others. The second is based on the theory of elasto-plasticity and has been used in the hydrobiomechanical multi-field coupling model (McDougall, 2007), the creep and biodegradation elasto-plastic model (Babu et al., 2010), the reinforced composite material model (Machado et al., 2008; Zhang, 2008) and others. Existing non-linear elastic models, which are relatively simple in forms and convenient for engineering applications such as stability analyses of linear systems (Reddy et al., 1996) and failure analyses of lined waste impoundments (Filz et al., 2001), are usually based on the generalised incremental Hooke's law. Unfortunately, most of them do not take into account the coupling effect between the mean normal stress $p$ and the deviatoric stress $q$; therefore, they can

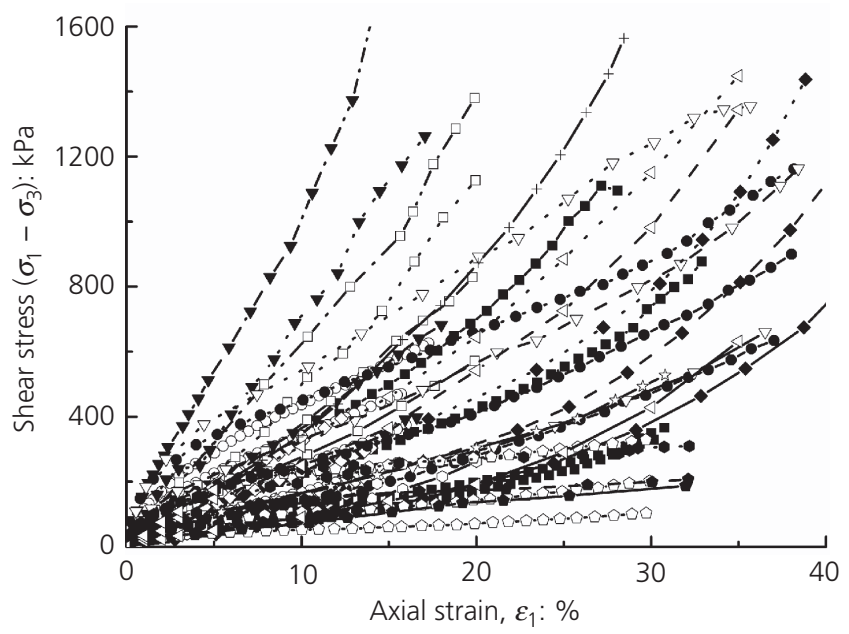

(a)
.... Reddy et al. (2009) - 276 kPa

一ー Gomes et al. (2005) - $100 \mathrm{kPa}$

-o- Itoh et al. (2005) - $40 \mathrm{kPa}$

- o- Itoh et al. (2005) - $60 \mathrm{kPa}$

-+- Zekkos (2005) - $75 \mathrm{kPa}$

$-\triangleleft-$ Gomes et al. (2013) - $35 \mathrm{kPa}$

- $\triangleleft-$ Gomes et al. (2013) - $140 \mathrm{kPa}$

.•৬. - Gomes et al. (2013) - $180 \mathrm{kPa}$

- - Jessberger and Kockel (1993) - $100 \mathrm{kPa}$

- - - Jessberger and Kockel (1993) - 200 kPa

..ロ. J Jessberger and Kockel (1993) - 300 kPa

-•-• Jessberger and Kockel (1993) - 400 kPa

- - Machado et al. (2002) - $100 \mathrm{kPa}$

- - Machado et al. (2002) - $200 \mathrm{kPa}$

... Machado et al. (2002) - $400 \mathrm{kPa}$
- - Reddy et al. (2009) - $69 \mathrm{kPa}$

- - Reddy et al. (2009) - $138 \mathrm{kPa}$

Figure 1. Summary of stress-strain responses of MSW: (a) original; (b) normalised 
hardly reflect the dilatancy behaviour of MSW. Compared with non-linear elastic models, elasto-plasticity-based models have a more rigorous theoretical basis and can be applied to complex stress path simulations. However, they usually have a more complex form and have relatively more difficulty in obtaining model parameters.

The goal of this paper is to present a non-linear elastic model for the prediction of the stress-strain behaviour of MSW. The dilatancy behaviour of MSW is first discussed based on triaxial compression test results. A model with four moduli is then proposed, and the moduli are formulated based on the results of isotropic consolidation and triaxial compression tests. Finally, the proposed model is used to simulate test results originating both from published studies and from the authors' laboratory testing.

\section{The dilatancy behaviour of MSW}

The dilatancy behaviour of soils or MSW is defined as the volume changes of soils when shear distortion is applied (Meschyan, 1998). The strength and deformation behaviours of soils are impacted by the dilatancy behaviour. Laboratory experiments show that when normally consolidated clay is subjected to a constant shear stress, extra pore-water pressure will be observed under undrained conditions, so that the effective stress will decrease. If drainage is allowed, a change in the void ratio will occur, and the volume will become stable over a short time. For heavily overconsolidated clays, the opposite situation often occurs (Bjerrum et al., 1958). Therefore, two different sets of dilatancy indices have to be used in these two different drainage conditions. According to Oweis et al. (1990), Reddy et al. (2009) and Beaven et al. (2011), the hydraulic conductivity of MSW varies from $10^{-2}$ to $10^{-6} \mathrm{~cm} / \mathrm{s}$ with the influence of the degree of compaction, age, degree of decomposition, gas content and temperature. Usually, almost no pore-water pressure should develop, as liquid can rapidly escape from the landfill mass, and primary settlement will occur rather quickly in a completed landfill (Gomes et al., 2014; Wall and Zeiss, 1995). Thus, this study is mainly concerned with the behaviour of drained MSW.

A series of laboratory experiments with MSW was conducted on samples from different depths with different ages from the Chengdu Changan landfill, China. Samples were prepared in the following way.

- For fresh waste, specimens were made directly on the triaxial apparatus.

- For the waste from a certain depth and of a certain age, a cylinder of $103 \mathrm{~mm}$ internal diameter and $240 \mathrm{~mm}$ height was used for sample preparation. Before the experiments, the specimens were subjected to a compressive pre-stress in order to recover their original stress state.

After sample installation, the specimens were saturated and consolidated under a certain confining pressure for about $24 \mathrm{~h}$. They were then subjected to shear stress at a strain rate of $0.4 \mathrm{~mm} / \mathrm{min}$.
The values of the pore-pressure coefficients $A_{\mathrm{f}}$ (the values of the pore-pressure coefficients $A$ when the specimens were sheared to different levels of axial strain) were measured in these tests. The results are presented in Figure 2. This coefficient is also used to define the degree of dilatancy of saturated soils (Skempton, 1954). If it is smaller than $1 / 3$, soils will dilate when subjected to shear stress. On the contrary, if it is greater than $1 / 3$, soils will contract when subjected to shear stress. It can be seen from Figure 2 that almost all the $A_{\mathrm{f}}$ values of the specimens at different depths and ages were greater than $1 / 3$, indicating the volume reduction of the MSW.

\section{A four-modulus non-linear elastic model}

There exist some non-linear elastic models that can take dilatancy behaviour into account based on traditional soil mechanics, such as those proposed by Izumi et al. (1976), Graham and Houlsby (1983) and Yin et al. (1990). In general, such models are usually expressed in the following two forms

$$
\begin{array}{r}
\mathrm{d} \varepsilon_{\mathrm{V}}=\frac{\mathrm{d} p}{K}+\frac{\mathrm{d} q}{H} \\
\mathrm{~d} \gamma=\frac{\mathrm{d} p}{G_{\mathrm{p}}}+\frac{\mathrm{d} q}{3 G} \\
\mathrm{~d} \varepsilon_{\mathrm{V}}=\frac{\mathrm{d} p}{K}+\frac{\mathrm{d} q}{H} \\
\mathrm{~d} \gamma=\frac{\mathrm{d} q}{3 G}
\end{array}
$$

Compared with Equation 2, Equation 1 can also take hardening behaviour into account. The moduli $K, H, G_{\mathrm{p}}$ and $G$ are the bulk modulus, dilatancy modulus, hardening modulus and shear modulus, respectively. These four moduli are usually dependent on the stress states of the soil, which are described by the mean normal stress and shear stress, or only one of them.

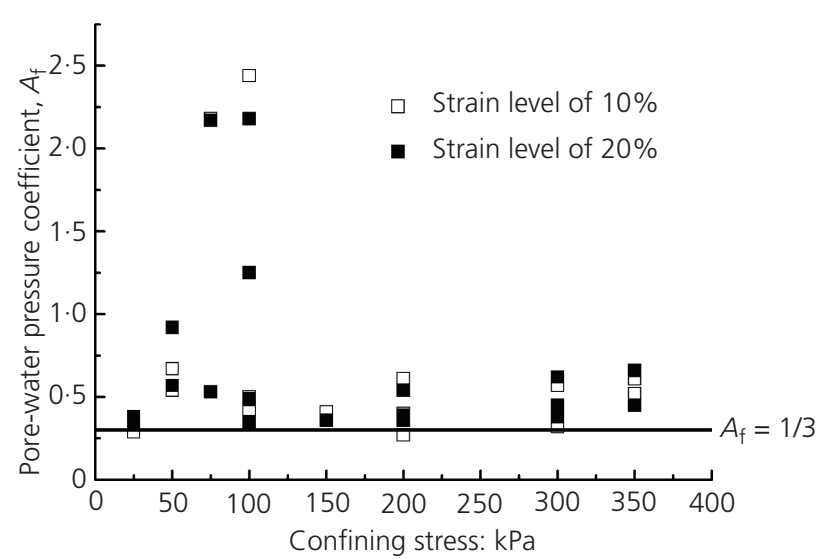

Figure 2. Pore-water pressure coefficient $A_{f}$ of MSW specimens 
Izumi et al. (1976) used a finite-element method to simulate excavation experiments conducted in an area composed of alluvial ground formed by the Arakawa River in Tokyo. The soil constitutive model used during the simulation was in the form of Equation 2 with three moduli. Graham and Houlsby (1983) proposed mathematical techniques for describing the pre-yield mechanical properties of natural clays by using anisotropic elasticity theory and for determining appropriate material parameters from triaxial test data. The model they proposed is in the form of Equation 1, and the hardening and dilatancy moduli were the same in their model. Yin et al. (1990) used data from isotropic consolidation tests and consolidated undrained triaxial tests with pore-water pressure measurements to form a constitutive model similar in form to Equation 1. This model was calibrated for different densities of a sand-bentonite 'buffer' proposed for nuclear fuel waste containment in Canada.

A common difficulty in establishing a model is the simulation of the volumetric strain of soil. For a material such as MSW, which shows obvious dilatancy behaviour, volumetric strain will be generated not only by mean normal stress, but also by shear stress during the loading process. Usually, non-linear elastic models are established using a total strain method, such as the Duncan-Chang $E-v$ and $E-B$ models (Duncan and Chang, 1970; Duncan et al., 1980), while elasto-plastic models are established using an incremental method such as the Cam clay model (Roscoe et al., 1963). Compared with incremental methods, it is easier to give expressions for the parameters using a total strain method. A total strain method usually shows good applicability to general loading; unfortunately, it has some limitations in complex stress path simulations. Contrarily, incremental methods are more capable of simulating the stress-strain behaviour of MSW, but require supportive data from many stress path tests, which are quite scarce in MSW research or engineering practice. Given that MSW is usually subjected to general loading in a landfill, a model is established using the total strain method in this paper.

This paper aims to establish expressions of the four moduli in Equation 1 through triaxial compression tests. The total expressions of normalised volumetric strain and generalised shear strain are formulated first. Then, the incremental expressions are obtained by differentiating them. Soil mechanics' compression positive sign convention is used in establishing the model.

\section{Laboratory tests on artificial MSW samples}

Laboratory tests on artificial MSW samples were designed to study the strength and deformation behaviours of MSW. The ingredients of the samples were based on MSW specimens drilled from the Tianziling landfill in Hangzhou, China. The representative MSW samples were of the following average physical compositions (dry weight): vegetable leaves, flesh and bone (17.1\%); soil, stone, brick and coal $(56.9 \%)$; paper $(4 \cdot 2 \%)$; rubber $(0.6 \%)$; plastic $(6.7 \%)$; textile $(7 \cdot 6 \%)$; glass $(0.5 \%)$; metal $(1.2 \%)$; ceramics $(0 \cdot 3 \%)$; shell $(0 \cdot 4 \%)$; and grass and wood $(4 \cdot 5 \%)$. The preparation process was as follows. (a) First, the weights and particle sizes (or lengths) of all ingredients were determined. The ingredients were then mixed thoroughly to avoid segregation.

(b) The mixtures were then divided into six parts and used to fill a cylindrical mould in six layers.

(c) Finally, the MSW samples were prepared in a specimen tube. Negative pressures were used at the top of the tube to mould the samples.

Triaxial compression tests were carried out using these samples with a nominal unit weight of $10.6 \mathrm{kN} / \mathrm{m}^{3}$, height of $600 \mathrm{~mm}$, diameter of $300 \mathrm{~mm}$ and initial void ratio of 3 . The sizes of the samples were at least ten times larger than the size of the largest element. Before the tests, the samples were saturated and then consolidated under specified confining pressures until the primary consolidation process was complete. Effective confining pressures of $100,200,300$ and $400 \mathrm{kPa}$ and a strain rate of $0.01 \mathrm{~mm} / \mathrm{s}$ were used in the triaxial compression tests.

The triaxial compression test results are presented in Figures 3 and 4. It can be seen that the shear stress continuously increased together with the axial strain and that failure did not occur even when the strain level was over 15\%. According to the volumetric strain against axial strain curves, the volumetric strain generated under higher confining pressure was lower than the value under lower confining pressure. The reason for this lies in the fact that the void ratio of the samples under higher confining pressure is lower after consolidation, so the rigidity of the samples becomes higher. The four moduli of the proposed model were established on the basis of the preceding test results as an example in this paper.

\section{The expression for volumetric strain}

In an isotropic consolidation test, the sample is subjected to a hydrostatic pressure, namely $p=\sigma_{1}^{\prime}=\sigma_{2}^{\prime}=\sigma_{3}^{\prime}$. Domaschuk and Valliappan (1975) suggested that the volumetric strain of a sample

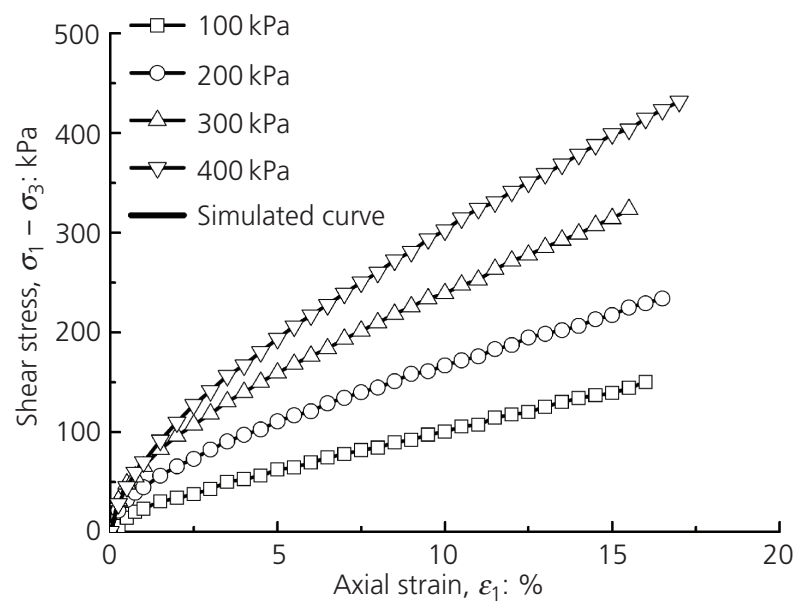

Figure 3. Shear stress against axial strain curves of MSW in CD conditions 


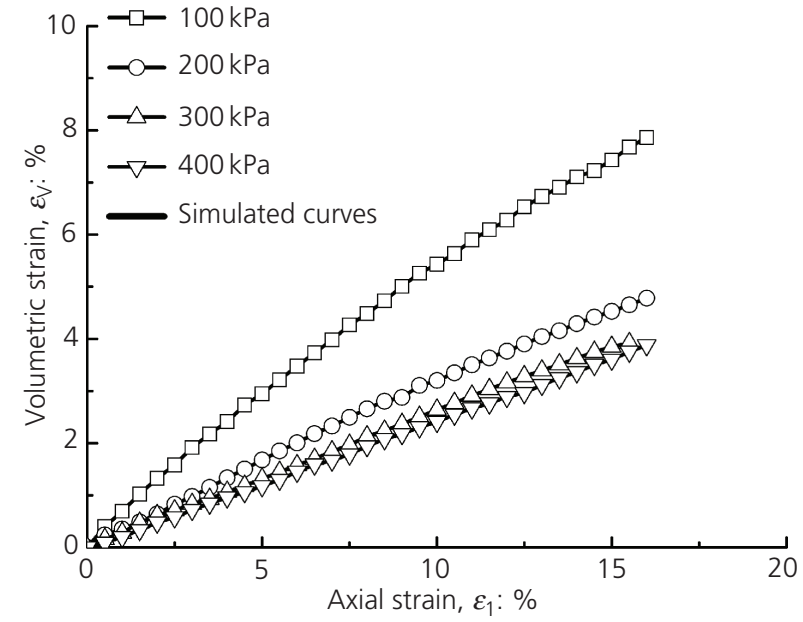

Figure 4. Volumetric strain against axial strain curves in $C D$ conditions

can be obtained from an isotropic consolidation test by finding the relationship between the variation in the void ratio during the test and the initial void ratio of the sample. Similar to conventional soil mechanics, the relationship between volumetric strain and the natural logarithm of mean normal stress is almost a straight line in isotropic consolidation tests of MSW, which are presented in Figure 5 (Nader et al., 2009; Shi et al., 2001). Equation 3 is the fitting equation of the predicted line. The values of parameters $\varepsilon_{\mathrm{V} 0}$ and $\lambda_{1}$ are -0.0314 and $0 \cdot 0446$, respectively, in this paper, with the samples' initial void ratio of 3 as an example. Equation 4 is the differential form of Equation 3, and it can be used to obtain the bulk modulus under isotropic consolidation conditions

3. $\varepsilon_{\mathrm{V}}=\varepsilon_{\mathrm{V} 0}+\lambda_{1} \ln p$

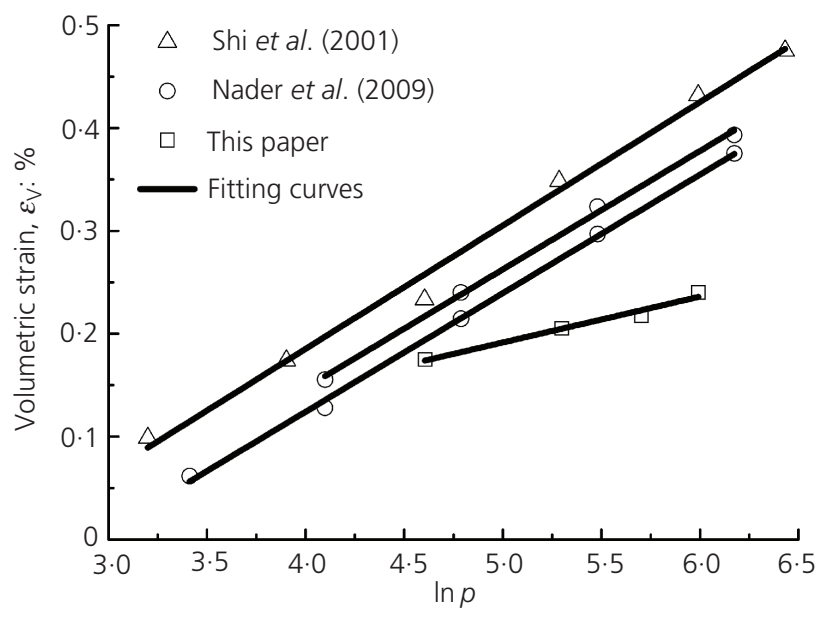

Figure 5. $\varepsilon_{V}-\ln p$ relationship of MSW in isotropic consolidation conditions
4. $K_{\mathrm{p}}=\frac{\mathrm{d} p}{\mathrm{~d} \varepsilon_{\mathrm{V}}}=\frac{p}{\lambda_{1}}$

(Since the proposed model is suitable for drainage conditions, the total and effective mean normal stresses $p$ are the same in the proposed model.)

For the general state of stress, volumetric strain was generated not only by mean normal stress, but also by shear stress during the loading process. Thus, the volumetric strain can also be divided into two parts, generated by mean normal stress and by shear stress.

5. $\varepsilon_{\mathrm{V}}=\varepsilon_{\mathrm{Vp}}+\varepsilon_{\mathrm{Vq}}$

where $\varepsilon_{\mathrm{Vp}}$ is the volumetric strain generated by the mean normal stress and $\varepsilon_{\mathrm{Vq}}$ is that generated by the shear stress. The volumetric strain calculated here is based on the initial MSW specimens in an unstressed state.

It is assumed that $\varepsilon_{\mathrm{Vp}}$ can be calculated based on the relationship between volumetric strain and the natural logarithm of the mean normal stress under an isotropic consolidation condition in the form of Equation 3. A square function composed of the mean normal stress and the shear stress is formulated based on test results to describe the volumetric strain generated by shear stress $\varepsilon_{\mathrm{Vq}}$, presented as

6. $\varepsilon_{\mathrm{Vq}}=f(p, q)=a\left(\frac{q}{p}\right)^{2}$

Then, the total volumetric strain can be described in the form of Equation 7 , where $\varepsilon_{\mathrm{V} 0}, \lambda_{1}$, and $a$ are model parameters

7.

$$
\varepsilon_{\mathrm{V}}=\varepsilon_{\mathrm{Vp}}+\varepsilon_{\mathrm{Vq}}=\varepsilon_{\mathrm{V} 0}+\lambda_{1} \ln p+a\left(\frac{q}{p}\right)^{2}
$$

The fitting results of the volumetric strain calculated by Equations 3 and 7 are presented in Figure 6. The fitting results are in good agreement with the volumetric strain values when Equation 7 is used, but are not satisfactory when using Equation 3, indicating the obvious necessity of including dilatancy behaviour in the presented model. The value of the parameter $a$ is 0.0336 in this case.

The test results presented in Figures 3 and 4 are based on the consolidated state under specified confining pressures, whereas the test results presented in Figure 6 as well as the volumetric strain calculated using Equations 3 and 7 are based on the initial MSW specimens with an unstressed state. According to the definition of volumetric strain, if $V_{0}$ is taken to be the initial 
Non-linear elastic model for MSW

considering dilatancy effect

Ke, Chen, Dong, Guo and Feng

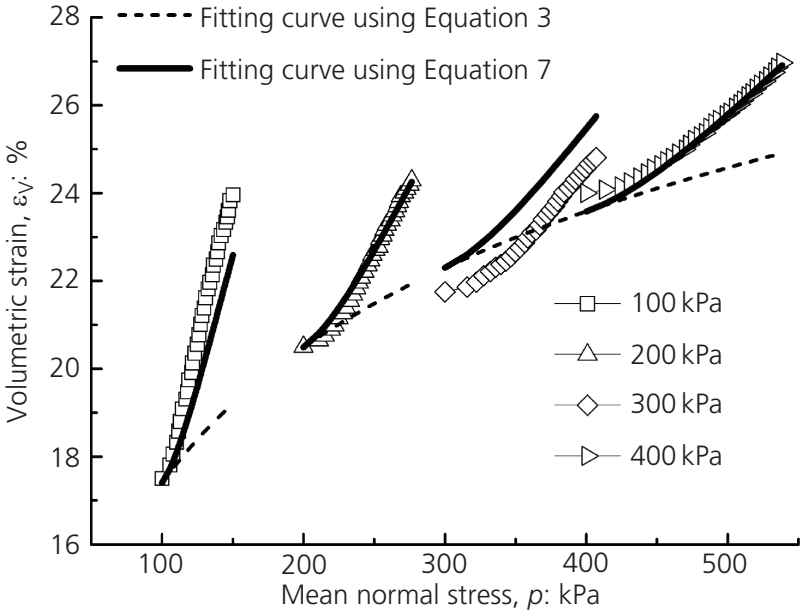

Figure 6. Experimental and simulated MSW volumetric strain against mean normal stress curves

volume of the specimen and $V_{1}$ is the volume of the consolidated state under a specified isotropic confining pressure $p_{1}$, the volumetric strain $\varepsilon_{\mathrm{V} 1}$ generated in this consolidation process can be calculated by Equation 7 with $p=p_{1}$ and $q=0$

8. $\varepsilon_{\mathrm{V} 1}=\frac{V_{0}-V_{1}}{V_{0}}$

Supposing that a triaxial compression test is carried out and that the increments of mean normal stress and shear stress are $\Delta p$ and $\Delta q$, respectively, the accumulated volumetric strain $\varepsilon_{\mathrm{V} 2}$ (which is based on the unstressed state) generated in the consolidation and loading process can be calculated by Equation 7 with $p=p_{1}+\Delta p$ and $q=\Delta q$ as

9. $\varepsilon_{\mathrm{V} 2}=\frac{V_{0}-V_{2}}{V_{0}}$

where $V_{2}$ is the volume of the specimen after $\Delta p$ and $\Delta q$ are applied. The volumetric strain based on the unstressed state generated from the triaxial test can be obtained from the difference between the volumetric strains determined after consolidation and loading, and after consolidation alone

10. $\varepsilon_{\mathrm{V}}=\varepsilon_{\mathrm{V} 2}-\varepsilon_{\mathrm{V} 1}=\frac{V_{1}-V_{2}}{V_{0}}$

However, the test results presented in the literature are usually based on the consolidated state under specified confining pressures - that is, they have the form

11. $\varepsilon_{\mathrm{V}}^{\prime}=\frac{V_{1}-V_{2}}{V_{1}}$
Thus, the volumetric strain calculated by Equation 7 should be multiplied by $V_{0} / V_{1}$ to match the test results presented in Figures 3 and 4. This multiplier can be obtained from Equation 8

12. $\frac{V_{0}}{V_{1}}=\left(1-\varepsilon_{\mathrm{V} 1}\right)^{-1}=\left(1-\varepsilon_{\mathrm{V} 0}-\lambda_{1} \ln p_{1}\right)^{-1}$

This method can be used to realise the transition between the systems based on the unstressed state and based on the isotropic consolidated state.

Equation 13 is the differential form of Equation 7 and can be used to obtain the bulk and the dilatancy modulus under $\mathrm{CD}$ conditions

13. $\mathrm{d} \varepsilon_{\mathrm{V}}=\left(\frac{\lambda_{1}}{p}-\frac{2 a q^{2}}{p^{3}}\right) \mathrm{d} p+\frac{2 a q}{p^{2}} \mathrm{~d} q$

where $\left(\lambda_{1} / p-2 a q^{2} / p^{3}\right)$ corresponds to $1 / K$ (which is called the bulk index), while $2 a q / p^{2}$ corresponds to $1 / H$ (which is called the dilatancy index) in Equation 1.

\section{The expression of generalised shear strain}

Generalised shear strain (namely $\gamma=2\left(\varepsilon_{1}-\varepsilon_{2}\right) / 3$ in the condition of triaxial tests) against shear stress curves under different confining pressures with the samples' initial void ratio of 3 are presented in Figure 7. Since the test results were significantly impacted by confining pressures, a normalised curve was used to establish a general formula to describe the generalised shear stress. The function expressed in Equation 14 was chosen to describe the shear stress as a normalised formula, where $m$ and $c$ are model parameters. A constant

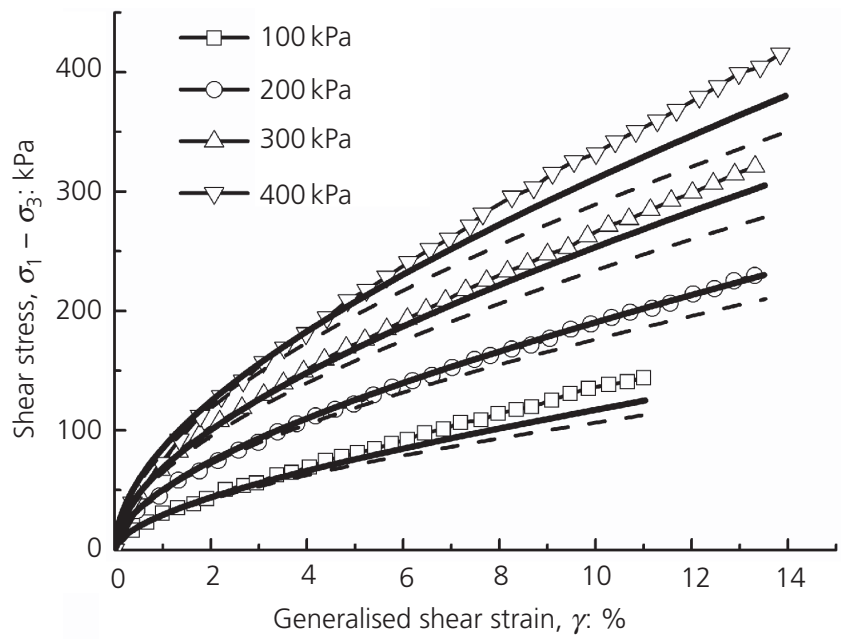

Fitting curves with the influence of hardening modulus - - Fitting curves without the influence of hardening modulus

Figure 7. Generalised shear strain against shear stress curves in CD conditions 
$p_{0}$ with a value of $1 \mathrm{kPa}$ was used for dimensional homogeneity. Figure 8 presents the normalised and fitting curves of the generalised shear strain with $m$ having a value of 0.74 and $c$ having a value of 0.0096. The normalisation effect was excellent and the fitting results were in good agreement with the experimental values

14. $\gamma=c\left[\frac{q / p_{0}}{\left(p / p_{0}\right)^{m}}\right]^{2}$

Equation 15 is the differential form of Equation 14 and can be used to obtain the hardening and shear moduli under $\mathrm{CD}$ conditions

$$
\begin{aligned}
\mathrm{d} \gamma & =-c \frac{2 m q^{2}}{p^{2 m+1}} p_{0}^{2(m-1)} \mathrm{d} p+c \frac{2 q}{p^{2 m}} p_{0}^{2(m-1)} \mathrm{d} q \\
& =c\left(-\frac{2 m q^{2}}{p^{2 m+1}} \mathrm{~d} p+\frac{2 q}{p^{2 m}} \mathrm{~d} q\right) p_{0}^{2(m-1)}
\end{aligned}
$$$$
15 .
$$

where $-c\left(2 m q^{2} / p^{2 m+1}\right) p_{0}^{2(m-1)}$ corresponds to $1 / G_{\mathrm{p}}$ (the hardening index), while $-c\left(2 q / p^{2 m}\right) p_{0}^{2(m-1)}$ corresponds to $1 / 3 G$ (the shear index) in Equation 1.

The fitting results of shear strain against shear stress curves using Equation 14 are also presented in Figure 7, with the fitting results irrespective of the effects of the hardening modulus. It can be seen that the shear strain decreases with the hardening effects and that the influence is more obvious as the shear stress increases. In general, the hardening effect is not as significant as the dilatancy effect.

In conclusion, the total and differential expressions of volumetric strain and generalised shear strain are given in Equations 7 and 13 as well as Equations 14 and 15, respectively, and can be summarised as Equations 16 and 17

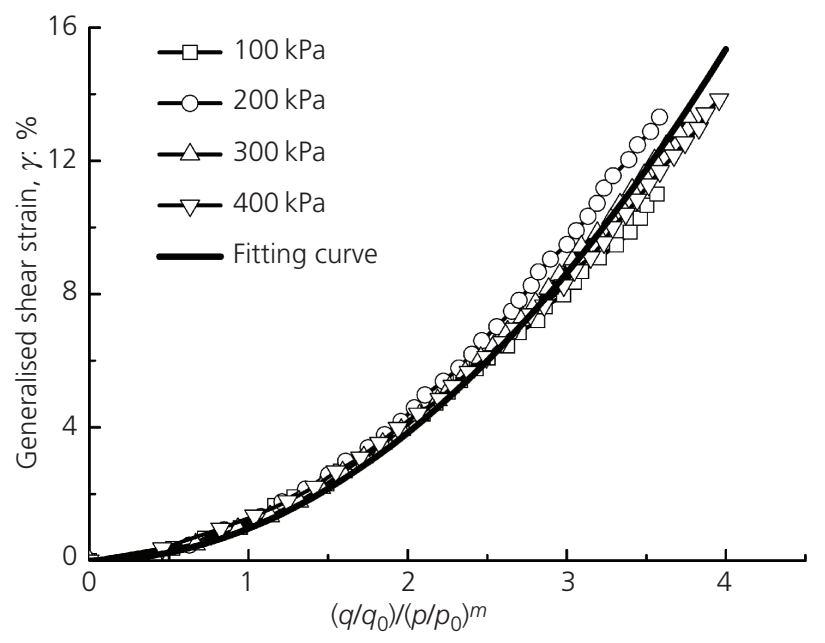

Figure 8. Normalised curves and quadratic fitting curve of generalised shear strain

$$
\begin{aligned}
& \varepsilon_{\mathrm{V}}= \varepsilon_{\mathrm{V} 0}+\lambda_{1} \ln p+a\left(\frac{q}{p}\right)^{2} \\
& \text { 16. } \gamma=c\left[\frac{q / p_{0}}{\left(p / p_{0}\right)^{m}}\right]^{2} \\
& \mathrm{~d} \varepsilon_{\mathrm{V}}=\left(\frac{\lambda_{1}}{p}-\frac{2 a q^{2}}{p^{3}}\right) \mathrm{d} p+\frac{2 a q}{p^{2}} \mathrm{~d} q \\
& \mathrm{~d} \gamma=c\left(-\frac{2 m q^{2}}{p^{2 m+1}} \mathrm{~d} p+\frac{2 q}{p^{2 m}} \mathrm{~d} q\right) p_{0}^{2(m-1)}
\end{aligned}
$$

Thus, a non-linear elastic model with four moduli that can take the dilatancy and hardening behaviours of MSW into account was established. The parameters $\varepsilon_{\mathrm{V} 0}$ and $\lambda_{1}$ can be obtained from isotropic consolidation tests, whereas the parameters $a, c$ and $m$ can be determined from triaxial compression tests. As presented in Figure 1, the stress-strain responses of MSW vary greatly. Some of them are described by convex functions (like 'A'), while some are described by concave functions (like ' $\mathrm{V}$ '). The proposed model belongs to the former category and generates larger deformation under the same stress level. In other words, it is more conservative than the latter for shear deformation prediction.

\section{Test simulation}

In order to examine the applicability of the proposed model further, some simulations of stress-strain and volumetric strain against axial strain results obtained from triaxial compression tests were carried out on samples from the Bandeirantes sanitary landfill (Machado et al., 2002; Vilar and Carvalho, 2004) and from the Changan landfill (current study).

When simulating test results, if there is an isotropic consolidation test result, $\varepsilon_{\mathrm{V} 0}$ and $\lambda_{1}$ can first be determined by matching it. Then, the parameters $c$ and $m$ can be determined by adjusting the simulated curve to match the shear stress against axial strain curve. Finally, the parameter $a$ can be determined by matching the volumetric strain against axial strain curve. However, isotropic consolidation test results of the samples mentioned earlier are not available, so the parameters can be determined only tentatively by fitting test results as follows. At the beginning, a rough simulation of the shear stress against axial strain curve can be made to give a preliminary value of the parameters $c$ and $m$; then, $\varepsilon_{\mathrm{V} 0}, \lambda_{1}$ and $a$ can be adjusted simultaneously to match the volumetric strain against axial strain curves. Finally, $c$ and $m$ can be determined by elaborately simulating the test results. For these cases, the fitting results only exhibit the simulated effects and the model parameters obtained may be different from the real ones.

\section{Simulations using the data of Machado et al. (2002)}

Machado et al. (2002) performed extensive laboratory tests on samples collected through two boreholes drilled in the Bandeirantes 
Non-linear elastic model for MSW

considering dilatancy effect

$\mathrm{Ke}$, Chen, Dong, Guo and Feng sanitary landfill, located in São Paulo, Brazil. The waste samples used in the laboratory tests were about 15 years old and had the following average physical compositions by dry weight: wood $(4 \%)$, paper $(2 \%)$, plastic $(17 \%)$, textile $(3 \%)$, metal $(5 \%)$, glass $(2 \%)$, rubber $(2 \%)$, stone $(10 \%)$ and paste $(55 \%)$. The paste included organic matter and a varying proportion of soil.

CD triaxial compression tests were carried out using statically compacted specimens with a nominal unit weight of $10 \mathrm{kN} / \mathrm{m}^{3}$, diameters of 150 and $200 \mathrm{~mm}$ and heights of 300 and $400 \mathrm{~mm}$, with a strain rate of $0.7 \mathrm{~mm} / \mathrm{min}$. Effective confining pressures of 100,200 and $400 \mathrm{kPa}$ were used, and each loading stage lasted about $15 \mathrm{~d}$. Typical results obtained from the triaxial compression tests and simulation curves are presented in Figure 9, including a shear stress against axial strain curve and a volumetric strain against axial strain curve.

It can be seen from Figure 9 that the values of shear stress obtained from the simulation results are good approximations of the test results. The simulation results also fit the volumetric strain of the test results of Machado et al. (2002) up to $20 \%$ of axial strain fairly well. For higher values of confining pressure, there is a tendency to overestimate the values of volumetric strain; for lower values of confining pressure, the values of volumetric strain over $20 \%$ of axial strain are somewhat underestimated.

\section{Simulations using the data of Vilar and Carvalho (2004)}

Vilar and Carvalho (2004) also collected MSW samples from the Bandeirantes sanitary landfill and performed a series of laboratory tests on them, including CD triaxial compression tests. The average proportion of organic paste for all samples was around $55 \%$. It is also worth noting the large proportion of plastic components (about 17\%) in the waste. The nominal unit weight of the samples was about $12 \mathrm{kN} / \mathrm{m}^{3}$, and the size, strain rate and effective confining pressures used were all the same as in the triaxial tests conducted by Machado et al. (2002). Saturated samples and samples moulded at the natural moisture content $(67 \%)$ were both tested. Typical results and simulation curves for samples moulded at natural moisture content and for saturated samples obtained from triaxial compression tests are presented in Figures 10 and 11, respectively.

Figures 10 and 11 show that there is good agreement between the experimental values of the volumetric strain and the simulations obtained from the proposed model at lower and higher percentages of axial strain for both the saturated and natural cases. For the natural cases, the simulations of shear stress fit the test results fairly well. For saturated samples, as the shear stress develops rapidly under higher strain, the simulations seem to digress from experimental values over $25 \%$ of the axial strain under different confining pressures.

\section{Simulations for Chengdu Changan landfill}

A series of laboratory tests were performed on samples collected through boreholes drilled at the Chengdu Changan landfill in Sichuan province, China. A batch of these samples was collected from depths of 5-15 m. In preparing the samples, large particles and sharp glass were removed, and plastics of large size were also cut into pieces. All the ingredients were thoroughly mixed to avoid segregation and the samples were pre-pressed under a pressure corresponding to their depth in order to recover their initial state of stress. The representative samples were $100 \mathrm{~mm}$ in diameter and $200 \mathrm{~mm}$ high.

CD triaxial compression tests were carried out on saturated samples that had been consolidated under a specified confining pressure for over $24 \mathrm{~h}$ under a strain rate of $0.3 \mathrm{~mm} / \mathrm{min}$. Effective confining pressures of $50,100,150$ and $250 \mathrm{kPa}$ were used in the

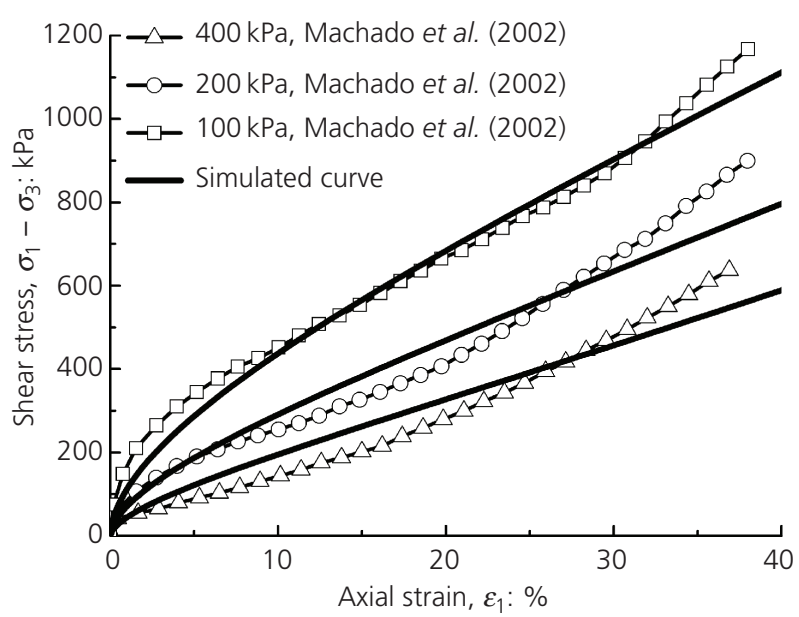

(a)

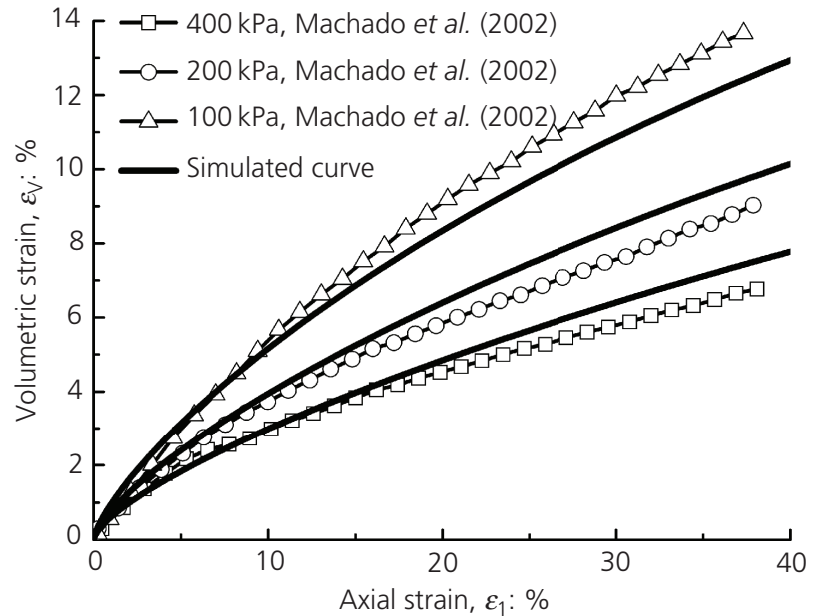

(b)

Figure 9. Typical results obtained from CD triaxial tests and simulated curves: (a) shear stress against axial strain curve; (b) volumetric strain against axial strain curve 
Environmental Geotechnics

Volume 6 Issue EG3
Non-linear elastic model for MSW

considering dilatancy effect

Ke, Chen, Dong, Guo and Feng

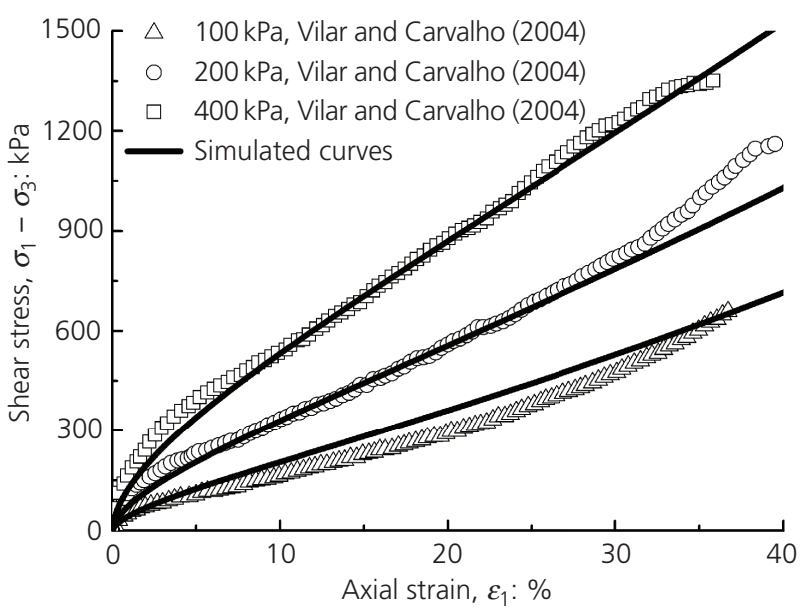

(a)

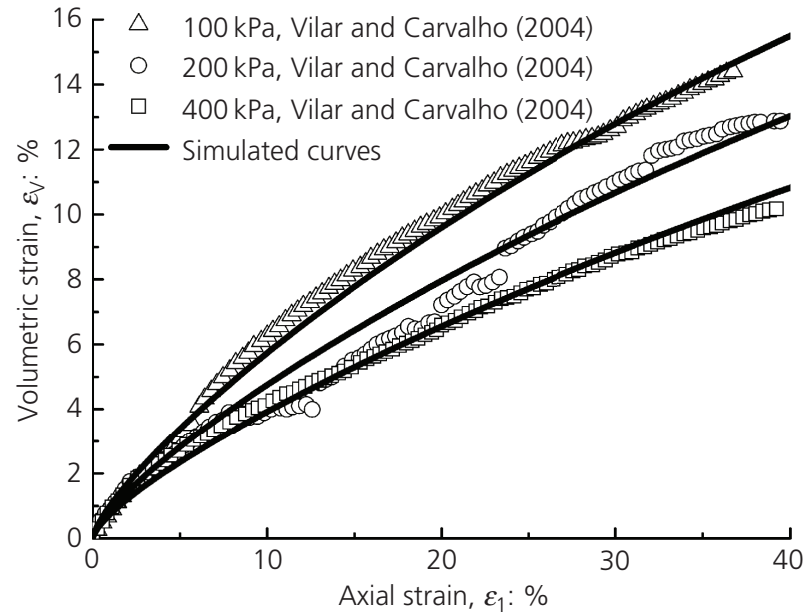

(b)

Figure 10. CD triaxial tests results and simulated curves on samples moulded at natural moisture content (67\%): (a) shear stress against axial strain curve; (b) volumetric strain against axial strain curve

tests. The test results and simulation curves are presented in Figure 12.

Figure 12 shows rough qualitative agreement between experimental and simulated values. As observed in the simulation results, the proposed model is able to capture the increasing trend of volumetric strain as the axial load increases continuously and compression of samples take place during the shearing process. The model is also capable of reproducing a decrease in volumetric strain as the confining stress increases.

The values of the model parameters obtained using the proposed models are presented in Table 1 . The parameters $\varepsilon_{\mathrm{V} 0}$ and $\lambda_{1}$ in Table 1 match those of the MSW samples taken from the same

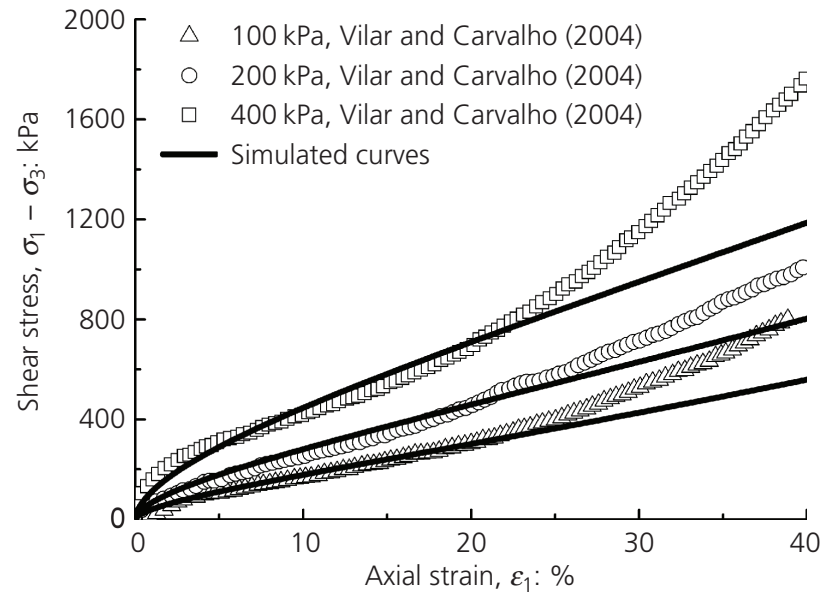

(a) place, while the other parameters differ from one another. Generally speaking, the values of the model parameters vary between MSW samples or test conditions, but fall within a relatively limited range.

The results presented in Figures 9-12 show that the proposed model can describe the dilatancy and hardening behaviours of MSW specimens. The stress-strain and volumetric strain behaviours of MSW under drained loading conditions can be modelled appropriately using the proposed constitutive model. However, since the high dispersion property of MSW becomes more significant with an increase in strain level, as presented in Figure 1, the proposed model cannot satisfy all cases or conditions. Therefore, the simulations will sometimes digress from experimental values under higher strain levels (e.g. higher than 20\%).

Figure 11. CD triaxial tests results and simulated curves on saturated samples: (a) shear stress against axial strain curve; (b) volumetric strain against axial strain curve

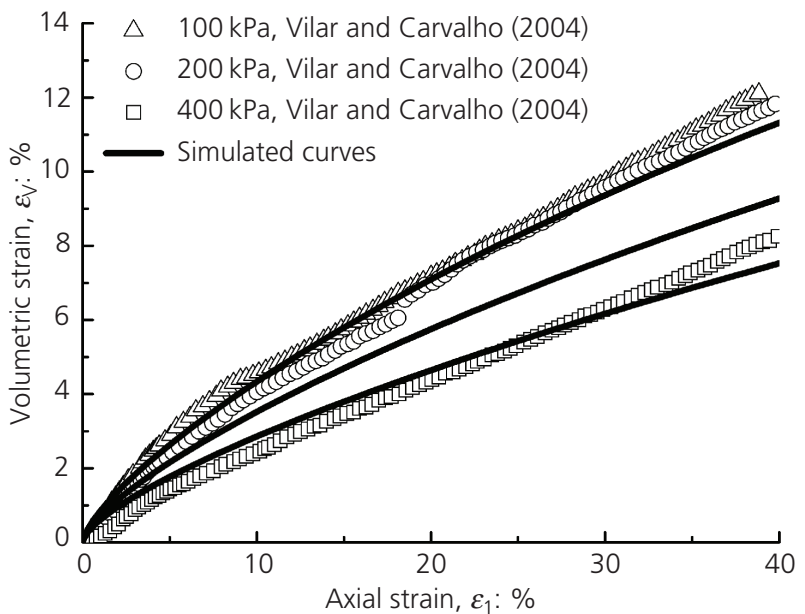

(b) 


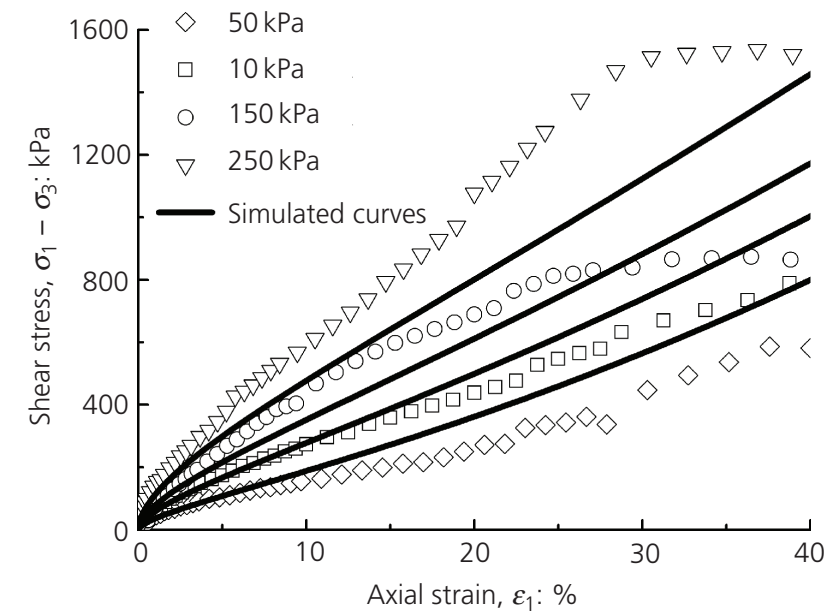

(a)

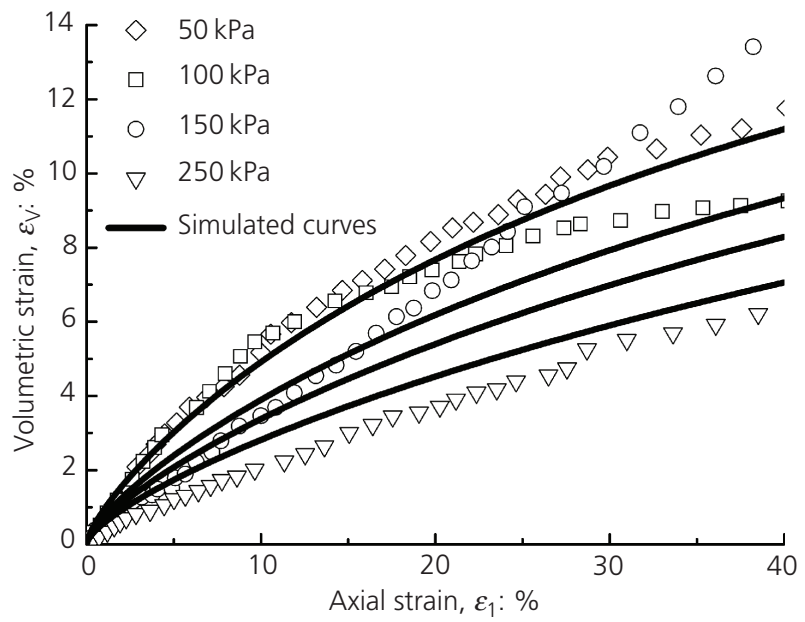

(b)

Figure 12. CD triaxial tests results and simulated curves on saturated samples: (a) shear stress against axial strain curve; (b) volumetric strain against axial strain curve

Table 1. Values of the five parameters

\begin{tabular}{llllll} 
& \multicolumn{3}{c}{ Parameter } \\
& \multicolumn{1}{c}{$\varepsilon_{\mathrm{V}}$} & $\lambda_{1}$ & \multicolumn{1}{c}{$c$} & $c$ \\
& -0.0314 & 0.0446 & 0.0336 & 0.0096 & 0.74 \\
This paper (man-made samples) & -0.3 & 0.053 & 0.02 & 0.0015 & 0.64 \\
Machado et al. (2002) & -0.2 & 0.05 & 0.02 & 0.004 & 0.745 \\
Vilar and Carvalho (2004) (natural moisture content) & -0.2 & 0.05 & 0.015 & 0.004 & 0.72 \\
Vilar and Carvalho (2004) (saturated condition) & -0.5 & 0.04 & 0.012 & 0.0016 & 0.69
\end{tabular}

\section{Conclusion}

A non-linear elastic, four-modulus constitutive model for MSW that considers the effects of dilatancy and hardening has been proposed based on existing triaxial CD tests. Simulations using the proposed model were performed for several sets of published data from $\mathrm{CD}$ triaxial compression tests conducted by other researchers. The main features and capabilities of the proposed model are as follows.

- The model was established using a total strain method. By dividing the shear stress by the power function of the mean normal stress, the generalised shear stress can be normalised. The formula gives the model the capability to take dilatancy and hardening behaviours of MSW into account.

- The model has a simple form that is suitable for engineering practice. Model parameters can be determined from isotropic consolidation tests and triaxial compression tests.

- The simulations are represented in the form of stress-strain responses and volumetric strain against axial strain. Good agreement was found between the stress-strain simulations and the experimental results. However, there were deviations in the simulations of volumetric strain for the high dispersion characteristics of MSW.
Finally, it should be noted that the MSW samples simulated in this work were of different ages, compositions and degradations. The influence of these factors on the stress-strain behaviour of MSW needs to be studied further.

\section{Acknowledgements}

Much of the work described in this paper was supported by the National Basic Research Program of China (973 Program) under grant number 2012CB719800 and the National Natural Science Foundation of China under grant number 51578503. The authors would like to acknowledge gratefully this financial support and express their most sincere gratitude.

\section{REFERENCES}

Babu GS, Reddy KR and Chouksey SK (2010) Constitutive model for municipal solid waste incorporating mechanical creep and biodegradation-induced compression. Waste Management 30(1): 11-22, https://doi.org/10.1016/j.wasman.2009.09.005.

Beaven RP, Powrie W and Zardava K (2011) Hydraulic properties of MSW. In Geotechnical Characterization, Field Measurement, and Laboratory Testing of Municipal Solid Waste (Zekkos D (ed.)). American Society of Civil Engineers, Reston, VA, USA, pp. 1-43, http://dx.doi.org/10.1061/41146(395)1.

Bjerrum L, Simons N and Torblaa I (1958) The effect of time on the shear strength of a soft marine clay. Proceedings of Conference on Earth Pressure Problems, Brussels, Belgium, vol. 1, pp. 148-158. 
Bray JD, Zekkos D, Kavazanjian E, Athanasopoulos GA and Riemer MF (2012) Shear strength of municipal solid waste. Journal of Geotechnical and Geoenvironmental Engineering 135(6): 709-722, https://doi.org/10.1061/(ASCE)GT.1943-5606.0000063.

Caicedo B, Giraldo E, Yamin L and Soler N (2002) The landslide of Dona Juana landfill in Bogota. Proceedings of the 4th International Congress on Environmental Geotechnics (4th ICEG), Rio de Janeiro, Brazil, pp. 171-175.

Chen YM, Gao D and Zhu B (2009) Composite exponential stress-strain model of municipal solid waste and its application. Chinese Journal of Geotechnical Engineering 31(7): 1020-1029.

Domaschuk L and Valliappan P (1975) Nonlinear settlement analysis by finite element. Journal of Geotechnical and Geoenvironmental Engineering 101(7): 601-614, https://doi.org/10.1016/0010-4485(76) 90116-0.

Duncan JM and Chang CY (1970) Nonlinear analysis of stress and strain in soils. Journal of Soil Mechanics and Foundations Division 96(5): $1629-1653$

Duncan JM, Wong KS and Mabry P (1980) Strength, Stress-Strain and Bulk Modulus Parameters for Finite Element Analysis of Stresses and Movements in Soil Masses. Department of Geotechnical Engineering, University of California, Berkeley, CA, USA.

Feng SJ (2005) Static and Dynamic Strength Properties of Municipal Solid Waste and Stability Analysis of Landfill. PhD thesis, Zhejiang University, Hangzhou, China.

Filz GM, Esterhuizen JJ and Duncan JM (2001) Progressive failure of lined waste impoundments. Journal of Geotechnical and Geoenvironmental Engineering 127(10): 841-848, https://doi.org/10.1061/(ASCE)10900241(2001)127:10(841)

Gomes C, Lopes ML and Lopes MG (2005) A study of MSW properties of a Portuguese landfill. Proceedings of International Workshop on Hydrophysico-mechanics of Landfills, Grenoble, France, vol. 1, pp. 1353-1360.

Gomes C, Lopes ML and Oliveira PJ (2013) Municipal solid waste shear strength parameters defined through laboratorial and in situ tests. Journal of the Air \& Waste Management Association 63(11) 1352-1368, https://doi.org/10.1080/10962247.2013.813876.

Gomes CC, Lopes ML and Oliveira PJV (2014) Stiffness parameters of municipal solid waste. Bulletin of Engineering Geology and the Environment 73(4): 1073-1087, https://doi.org/10.1007/s10064-0140621-9.

Graham J and Houlsby GT (1983) Anisotropic elasticity of a natural clay. Géotechnique 33(2): 165-180, http://dx.doi.org/10.1680/geot.1983.33. 2.165 .

Grisolia M, Napoleoni Q, Sirini P and Tancredi G (1991) Geotechnical behaviour of sanitary landfill based on laboratory and in-situ tests. Journal of Resource Management and Technology 20(4): 197-203.

Itoh T, Towhata I and Kawano Y (2005) Mechanical properties of municipal waste deposits and ground improvement. In Proceedings of the 16th International Conference on Soil Mechanics and Geotechnical Engineering. Balkema, Rotterdam, the Netherlands, vol. 16, pp. 2273-2276.

Izumi HK, Kamemura K and Sato S (1976) Finite element analysis of stresses and movements in excavations. Proceedings of the 2nd International Conference on Numerical Methods in Geomechanics, Blacksburg, VA, USA, pp. 701-712.

Jessberger HL and Kockel R (1993) Determination and assessment of the mechanical properties of waste materials. Proceedings, Sardinia, Italy, vol. 93, pp. 1383-1392.

Karimpour-Fard M, Machado SL, Shariatmadari N and Noorzad A (2011) A laboratory study on the MSW mechanical behaviour in triaxial apparatus. Waste Management 31(8): 1807-1819, https://doi.org/ 10.1016/j.wasman.2011.03.011.

Lopes MP (2014) Tensile properties of geosynthetics after installation damage. Environmental Geotechnics 1(3): 161-178, http://dx.doi.org/ 10.1680/envgeo.13.00032
Lopes ML and Gomes CC (2013) Geotechnical landfill monitoring adaptations needed. Environmental Geotechnics 2(1): 8-17, http://dx.doi.org/10.1680/envgeo.13.00014.

Machado SL, Carvalho MF and Vilar OM (2002) Constitutive model for municipal solid waste. Journal of Geotechnical and Geoenvironmental Engineering 128(11): 940-951, https://doi.org/10.1061/(ASCE)10900241(2002)128:11(940).

Machado SL, Vilar OM and Carvalho MF (2008) Constitutive model for long term municipal solid waste mechanical behaviour. Computers and Geotechnics 35(5): 775-790, https://doi.org/10.1016/j.compgeo. 2007.11.008

McDougall J (2007) A hydro-bio-mechanical model for settlement and other behaviour in landfilled waste. Computers and Geotechnics 34(4) 229-246, https://doi.org/10.1016/j.compgeo.2007.02.004.

Meschyan SR (1998) Dilatancy and contraction of clayey soils under simple shear. Soil Mechanics and Foundation Engineering 35(1): 13-16, https://doi.org/10.1007/BF02465974.

Nader S, Machado SL, Ali N and Mehran KF (2009) Municipal solid waste effective stress analysis. Waste Management 29(12): 2918-2930, https://doi.org/10.1016/j.wasman.2009.07.009.

Oweis IS, Smith DA, Ellwood RB and Greene DS (1990) Hydraulic characteristics of municipal refuse. Journal of Environmental Engineering 116(4): 539-553, https://doi.org/10.1061/(ASCE)07339410(1990)116:4(539).

Reddy KR, Kosgi S and Motan ES (1996) Interface shear behaviour of landfill composite liner systems: a finite element analysis. Geosynthetics International 3(2): 247-275, https://doi.org/10.1680/ gein.3.0062.

Reddy KR, Hettiarachchi H, Parakalla N et al. (2009) Hydraulic conductivity of MSW in landfills. Journal of Geotechnical and Geoenvironmental Engineering 135(8): 667-683, https://doi.org/ 10.1061/(ASCE)EE.1943-7870.0000031.

Roscoe KH, Schofield A and Thurairajah A (1963) Yielding of clays in states wetter than critical. Géotechnique 13(3): 211-240, http://dx.doi.org/10.1680/geot.1963.13.3.211.

Rowe RK (2014) Performance of GCLs in liners for landfill and mining applications. Environmental Geotechnics 1(1): 3-21, http://dx.doi.org/ 10.1680/envgeo.13.00031.

Shi JY, Lu TH and Zhu JG (2001) Experimental study on deformation behaviour of solid waste from Xiaping rubbish-dumping field. Journal of Hohai University 29(B12): 131-134.

Singh MK, Sharma JS and Fleming IR (2009) A design chart for estimation of horizontal displacement in municipal landfills. Waste Management 29(5): 1577-1587, https://doi.org/10.1016/j.wasman.2008.10.003.

Singh MK and Fleming IR (2011) Application of a hyperbolic model to municipal solid waste. Géotechnique 61(7): 533-547, http://dx.doi.org/ 10.1680/geot.8.P.051.

Skempton AW (1954) The pore-pressure coefficients A and B. Géotechnique 4(4): 143-147, https://doi.org/10.1680/geot.1954.4.4. 143.

Sun XL (2007) Characterization of Deformation and Strength for Municipal Solid Waste. PhD thesis, Dalian University of Technology, Dalian, China.

Vilar OM and Carvalho MF (2004) Mechanical properties of municipal solid waste. Journal of Testing and Evaluation 32(6): 438-449, https://doi.org/10.1520/JTE11945.

Wall DK and Zeiss C (1995) Municipal landfill biodegradation and settlement. Journal of Environmental Engineering 121(3): 214-224, https://doi.org/10.1061/(ASCE)0733-9372(1995)121:3(214).

Yin JH, Saadat F and Graham J (1990) Constitutive modelling of a compacted sand-bentonite mixture using three-modulus hypoelasticity. Canadian Geotechnical Journal 27(3): 365-372, https://doi.org/ 10.1139/t90-047.

Zekkos D (2005) Evaluation of Static and Dynamic Properties of Municipal Solid Waste. University of California, Berkeley, CA, USA. 
Zhan LT, Chen YM and Ling WA (2008) Shear strength characterization of municipal solid waste at the Suzhou landfill, China. Engineering Geology 97(3): 97-111, https://doi.org/10.1016/j.enggeo.2007. 11.006.

Zhang B (2008) Constitutive Modelling of Municipal Solid Waste. PhD thesis, Loughborough University, Loughborough, UK.

Zhang ZY, Wu DZ and Yan LJ (2014) Study on the non-linear shear strength properties of municipal solid waste. In Geoenvironmental
Engineering (Reddy KR and Shen S (eds)). American Society of Civil Engineers, Reston, VA, USA, GSP 241, pp. 90-99, http://dx.doi. org/10.1061/9780784413432.010.

Zhu JG, Shi JY and Yan Y (2002) Experimental study on the strength behaviour of solid waste. In Proceedings of the 1st Chinese Symposium on Geoenvironmental and Geosynthetics (Bao C and Chen Y (eds)). Zhejiang University Press, Hangzhou, China, pp. 192-196.

\section{How can you contribute?}

To discuss this paper, please submit up to 500 words to the editor at journals@ice.org.uk. Your contribution will be forwarded to the author(s) for a reply and, if considered appropriate by the editorial board, it will be published as a discussion in a future issue of the journal. 